University of Massachusetts Amherst

ScholarWorks@UMass Amherst

2018

\title{
Normal Utilization as the Adjusting Variable in Neo-Kaleckian Growth Models: A Critique
}

Daniele Girardi

Economics Department, University of Massachusetts Amherst

Riccardo Pariboni

Economics Department, Roma Tre University

Follow this and additional works at: https://scholarworks.umass.edu/econ_workingpaper

Part of the Economics Commons

\section{Recommended Citation}

Girardi, Daniele and Pariboni, Riccardo, "Normal Utilization as the Adjusting Variable in Neo-Kaleckian Growth Models: A Critique" (2018). UMass Economics Working Papers. 247.

https://doi.org/10.7275/12294937

This Article is brought to you for free and open access by the Economics at ScholarWorks@UMass Amherst. It has been accepted for inclusion in Economics Department Working Paper Series by an authorized administrator of ScholarWorks@UMass Amherst. For more information, please contact scholarworks@library.umass.edu. 


\title{
Normal utilization as the adjusting variable in Neo-Kaleckian growth models: a critique
}

\author{
Daniele Girardi* and Riccardo Pariboni**
}

June 2018

\begin{abstract}
As well-known, the canonical Neo-Kaleckian growth model fails to reconcile actual and normal rates of utilization in equilibrium. Some recent contributions revive an old proposal for solving this problem - making the normal rate of utilization an endogenous variable that converges to the actual utilization rate - justifying it with new, micro-founded premises. We argue that these new justifications for the convergence of normal to actual utilization do not stand closer scrutiny. First, the proposed microeconomic model relies on various restrictive assumptions, some of which are mutually inconsistent. Second, the derivation of the macroeconomic adjustment mechanism from the microeconomic analysis involves a logical leap, that can be justified only by a very arbitrary assumption with little economic justification. Finally, we discuss the way in which this mechanism has been incorporated into the Neo-Kaleckian growth model by proposers of this approach. We show that, even if one puts aside, for the sake of argument, the first two points, the existence of autonomous components of demand is sufficient to invalidate the resulting macroeconomic model.
\end{abstract}

Keywords: Capacity Utilization, Normal Rate of Utilization, Neo-Kaleckian model, Economic Growth

JEL Codes: B50, E11, E12, E22

* Department of Economics, University of Massachusetts, Amherst, dgirardi@umass.edu

** Department of Economics, Roma Tre University, riccardo.pariboni@uniroma3.it

We are grateful to Ariel Dvoskin, Saverio Fratini, Biao Huang and Peter Skott for helpful comments and discussions. The usual disclaimer applies. 


\section{Introduction}

The Neo-Kaleckian model of growth and distribution (Rowthorn, 1981; Dutt, 1984; Amadeo, 1986) has progressively imposed itself as an influential contribution to macroeconomic modelling, but it has also raised serious concerns. A main argument of contention, and major critique against the Neo-Kaleckian model, concerns its failure to reconcile the actual and normal ${ }^{1}$ rates of capacity utilization in equilibrium (Skott, 2012; Cesaratto, 2015). As recognized also by its proponents (e.g. Hein et al., 2012), within this model any attempt by firms to restore their desired rate of capacity utilization via changes in accumulation (as a standard accelerator model of investment would imply) would generate instability.

In order to avoid instability but maintain the other features of the Neo-Kaleckian model, some authors have proposed making the desired degree of capacity utilization itself an adjusting variable, which would simply adapt to the realized rate of utilization. Traditionally, this literature has justified adaptive behavior of the normal utilization rate on 'conventionalist' grounds: under fundamental uncertainty regarding market conditions, firms would just follow the conventional rule of treating any realized rate of utilization as their desired rate (Hein at al., 2012).

Some recent contributions, however, have proposed new (non-conventionalist) foundations for the convergence of the normal utilization rate to its current, actual value (Nikiforos, 2016; Dávila-Fernández et al., 2017). This approach relies on a microeconomic model in which firms minimize costs under (a particular type of) increasing returns to scale (Nikiforos, 2013). Specifically, the model would imply a positive effect of the firm's output level on the firm's desired utilization rate. It is then argued that this firm-level relation would imply, at the macro level, adaptation of the desired utilization rate to the observed realized rate, in such a way as to make the Neo-Kaleckian model stable (Nikiforos, 2016; Dávila-Fernández et al., 2017).

This paper argues that these recent micro-founded justifications for the convergence of desired to actual utilization do not stand closer scrutiny. We bring two main arguments in support of this negative conclusion. These two arguments are independent of one another.

\footnotetext{
${ }^{1}$ The normal rate (or degree) of utilization is the firms' target rate of utilization of their productive capacity, the one firms desire to achieve. Sometimes in the literature it is called 'desired' (or 'planned') rate of utilization. We use the two terms interchangeably.
} 
First, the microeconomic model on which this approach is based makes various restrictive assumptions. Specifically, the model relies on an ad-hoc specification of the cost functions. The arbitrary assumptions about production costs are directly conducive to the result that the analysis aims to prove. These assumptions are verbally justified by appealing to the real-world relevance of a specific kind of increasing returns to scale. In fact, as we will show, the cost functions do not actually imply increasing returns to scale according to the conventional definition. Moreover, some of the model's assumptions appear mutually inconsistent. As mentioned, the model aims to explore the consequences of increasing returns to scale. But in such a setting firms would enjoy substantial market power. And yet it is assumed that firms take both the output level and the price as given. In addition to this, the model employs a treatment of capital that has been proved untenable in the so-called Cambridge capital controversy (Sraffa, 1960; Pasinetti, 1966; Garegnani, 1990).

Second, the derivation of the macroeconomic adjustment mechanism from the microeconomic analysis involves a logical leap, that can be justified only by a rather peculiar aggregation process. It is assumed that the change in the average level of output per firm depends on the discrepancy between the actual and the expected aggregate growth rate of the economy, and that the variation in output per firm is exactly zero when the economy grows at its expected rate. As we will explain (Sec. 2.2), this assumption has no plausible economic justification. Proposers of the approach have provided an empirical justification (Nikiforos, 2016, pp. 453-454), which we show to be unconvincing as well: the model is actually hard to reconcile with simple time-series evidence.

Dávila-Fernández et al. (2017) use this micro-founded mechanism as the foundation for a Neo-Kaleckian growth model with endogenous normal utilization and an exogenous component in the accumulation function. We show that, even assuming that desired utilization does somehow adapt to the realized utilization rate, the existence of other sources of demand, besides domestic consumption and investment, is sufficient to lead the resulting macroeconomic model astray.

The paper is organized as follows. Section 1 reviews old and new proposals for solving the instability-problem of Neo-Kaleckian growth models, with a specific focus on the argument that desired utilization would adapt to actual utilization. We distinguish between the traditional 'conventionalist' arguments and the new micro-founded approach. In Section 2, we provide our critique of the 'new approach'. Our negative conclusions are supported by an analysis of the micro-level assumptions (2.1) and of the aggregation process that is used to derive macro-level conclusions (2.2 and 2.3); moreover, we show that the resulting macro-model is not robust to the inclusion of autonomous demand components (2.4). 


\section{Normal utilization as an adjusting variable: old and new approaches}

Several authors have proposed 'closing' the Neo-Kaleckian growth model with the assumption that the normal rate of capacity utilization is an 'adjusting' variable, which adapts to any realized rate of utilization. In the remainder of this Section, we discuss the justifications that have been offered in the literature for this assumption, distinguishing between 'conventionalist' explanations on the one hand, and the micro-founded approach proposed by some recent contributions on the other.

\subsection{The instability-problem in Neo-Kaleckian growth models}

A major critique that has been raised towards the Neo-Kaleckian growth model is that it is incapable of reconciling actual and normal rates of capacity utilization in equilibrium (Skott, 2012; Cesaratto, 2015). As recognized also by its proponents (e.g. Hein et al., 2012), within this model any attempt by firms to restore their desired degree of capacity utilization would generate instability of the Harrodian type.

To briefly summarize the problem, consider a basic Neo-Kaleckian model of a closed economy without public sector, which consists of two fundamental equations: ${ }^{2}$

$$
\begin{aligned}
& \mathrm{g}^{\mathrm{K}}=\mathrm{I} / \mathrm{K}=\gamma+\gamma_{\mathrm{u}}\left(\mathrm{u}-\mathrm{u}_{\mathrm{n}}\right) \\
& \mathrm{g}^{\mathrm{S}}=\mathrm{S} / \mathrm{K}=\mathrm{s}_{\mathrm{p}} \Pi \mathrm{u} / \mathrm{v}
\end{aligned}
$$

Equation (1) is a standard Neo-Kaleckian accumulation function, where accumulation depends on the entrepreneurs' expectations of the growth rate of demand $(\gamma), \gamma_{u}$ is a positive reaction coefficient, $u$ and $u_{n}$ are, respectively, the actual and the normal degree of capacity utilization. Equation (2) is the saving function, normalized by the capital stock: $s_{p}$ is capitalists' propensity to save (workers are assumed not to save), $\Pi$ is the profit share, $v$ is the normal capital-output technical coefficient.

From the equilibrium condition in the goods market $(\mathrm{I}=\mathrm{S})$, we can derive the equilibrium degree of capacity utilization:

${ }^{2}$ Our presentation of the standard Neo-Kaleckian model is based on Amadeo (1986). 


$$
u^{*}=\frac{\left(\gamma-\gamma_{u} u_{n}\right) v}{s_{p} \Pi-v \gamma_{u}}
$$

It seems reasonable to assume that entrepreneurs have adaptive expectations and revise their assessed growth rate as long as this diverges, for a certain span of time, from the actual growth rate of the economy (Hein et al., 2012, p. 144; Lavoie, 2014, p. 378). In terms of the basic Neo-Kaleckian model we have introduced, this would mean that a discrepancy between $u$ and $u_{n}$ induces a variation of the same sign in the parameter $\gamma$ :

$$
\Delta \gamma=\theta\left(\mathrm{u}^{*}-\mathrm{u}_{\mathrm{n}}\right)
$$

where $\theta$ is a positive reaction coefficient.

The introduction of equation 4, however, poses a major (Harrodian) instability-problem, as shown in Figure 1. Assume that at time 0 - when the accumulation rate and the saving function are described by $\left[\mathrm{gK}_{0}, \mathrm{~g}_{0}\right]$ - the equilibrium degree of capacity utilization is equal to the normal one. If the marginal propensity to save increases, the saving function rotates leftward and intersects the accumulation function at $\mathrm{u}_{1}$, with $\mathrm{u}_{1}<\mathrm{u}_{\mathrm{n}}$. Following equation (4), in the attempt to restore normal utilization, entrepreneurs will revise and lower their assessment of the trend growth rate. This means a downward shift of the accumulation function and results in a further diminution of $u: \mathrm{u}_{2}<\mathrm{u}_{1}<\mathrm{u}_{\mathrm{n}}$. This downward spiral would go on indefinitely, until $u$ approaches 0 . Symmetrically, a positive demand shock (such as a decrease in the marginal propensity to save) would cause an explosive, upward dynamics for the degree of capacity utilization.

\subsection{Three proposed solutions for the instability problem}

Various attempts have been made to deal with the instability problem that affects NeoKaleckian growth models. Following the comprehensive review of Hein et al. (2012), we can identify three main proposals:

1) There is no single desired degree of capacity utilization, but a range of acceptable values (Dutt, 1990; Setterfield, 2017). Therefore, any short-run equilibrium that falls within the admissible range can be treated as a long-run fully adjusted position, where no incentive for a change in the accumulation rate is at work.

2) The firm is characterized by conflicts of interests among social groups: shareholders against managers; capitalists against workers; different groups of shareholders against 
one another (Lavoie, 1992; Dallery and van Treeck, 2011). Given this, some authors have argued that "the equality of actual and normal rates of capacity utilization should not be treated as the (only possible) long-run equilibrium condition" (Hein et al., 2012, p. 154). Each social group has its own targets, which are not necessarily mutually compatible and tend to be in competition with one another. By allowing the equilibrium degree of capacity utilization to diverge from the normal one, conflicting interests would be - at least partially - reconciled.

3) The normal degree of capacity utilization itself may be assumed to be an endogenous variable, which would simply adapt to the realized rate of utilization. Hence, causality of the adjustment mechanism would be reversed: in case of discrepancies, it is the normal rate of capacity utilization that tends towards the actual one.

This third line of reasoning has traditionally been based on a 'conventionalist' argument: in a world characterized by uncertainty - including about future demand dynamics human behavior is driven by conventions. This applies also to firms' decisions, including the determination of the normal degree of capacity utilization. In this fundamentally uncertain context, firms would, by convention, treat any realized utilization rate as their desired one (see e.g. Lavoie et al., 2004). Recent contributions, however, have proposed different (non-conventionalist) foundations for the same mechanism of convergence of the normal utilization rate to its actual, realized value, based on a micro-founded costminimization process and the presence of increasing returns to scale (Nikiforos, 2013 and 2016; Dávila-Fernández et al., 2017).

It appears fair to say that the third proposal - convergence of the normal utilization rate to its actual rate - is the one that gained most traction. It is on this proposal, and in particular its most recent (micro-founded) rationalizations, that we focus in this paper. We thus abstain from discussing in detail the first two proposals. We limit ourselves to a brief summary ${ }^{3}$ of the reasons why several authors have considered them unsatisfactory. In the first proposal - a range of acceptable values rather than a single utilization rate Harrodian instability would be back whenever a change in some exogenous parameter displaces the provisional equilibrium outside the acceptable range for the equilibrium degree of capacity utilization. Given that, in a Neo-Kaleckian model, small changes in the saving rate are sufficient to cause large changes in the rate of utilization (Skott, 2018, p. 9 ), the range of acceptable utilization rates would need to be implausibly large in order to prevent Harrodian instability. The second proposal does not provide a compelling explanation of why internal distributional conflicts (which certainly exist) would prevent firms from changing their investment rate in reaction to over- or under-utilization of

${ }^{3}$ See Skott (2012), Cesaratto (2015) and Shaikh (2016) for more comprehensive expositions. 
existing capacity and lead them to accept a capacity utilization other than their target (Skott, 2012, p. 125).

\subsection{The traditional approach to normal utilization as an adjusting variable: normal utilization as a convention}

The most popular proposal for solving the instability problem - convergence of the desired rate of utilization to any realized value - implies 'closing' the stylized NeoKaleckian model constituted by equations (1) and (2) by means of the following equation:

$$
\dot{\mathrm{u}}_{\mathrm{n}}=\alpha\left(\mathrm{u}^{*}-\mathrm{u}_{\mathrm{n}}\right)
$$

where $\alpha$ is a positive parameter.

The traditional Neo-Kaleckian approach for justifying this mechanism is based on a conventionalist line of reasoning. Under fundamental uncertainty about market conditions, firms would just follow the convention of treating any realized utilization rate as their desired rate. This implies the adoption of a different notion of normal utilization, critically defined by Shaikh as "normal-as-situational" (Shaikh, 2016, p. 595), in which "the operating rate which firms come to 'desire' depends on what they happen to get" (ibid., p. 596).

Convincing critiques of this position have been presented in the literature. Nikiforos (2016) rightly argues that the need to be able to face unexpected demand oscillations is a firm's objective and a "non-conventional reason for keeping a part of its capacity idle" (Nikiforos, 2016, p. 444). Nikiforos notes that the endogeneity of the normal degree of capacity utilization based on uncertainty about demand volatility would imply that when the actual degree of capacity utilization is, for example, lower than its normal level, then entrepreneurs should expect "more volatile demand and thus decrease its desired rate of utilisation" (ibid.). However, no clear justification for this rule seems to emerge.

Skott (2012) draws a comparison and discusses the plausibility of different kinds of adaptive behavior: adaptive inflation expectations are, for example, a conceivable mechanism through which agents interact with inflation, a variable outside their control. The story is different with the postulated adaptability and endogeneity of the normal degree of capacity utilization: firms can react to capacity utilization levels different from their target level by adjusting their accumulation pattern, in order to restore normal utilization. It is not clear, then, why they should instead decide to come to terms with an outcome that is not their desired one. 
Overall, the picture that emerges from our discussion of these three proposals appears to be one in which adjustment mechanisms are appended in a rather ad-hoc way, with the aim of avoiding the emergence of instability in the model. Skott is therefore right, in our view, to suspect the existence of "an instability-based argument for adaptation" (Skott, 2012, p. 121), where the endogenous adjustment of $u_{n}$ would simply be a way to avoid Harrodian instability, and to criticize the soundness of a "purely functional argument" (ibid.).

1.4 A new approach: convergence of desired utilization to its current rate as a result of increasing returns

Some recent contributions, while rejecting the notion of the normal rate of utilization as a convention, have argued that it is possible to justify convergence of the normal utilization rate to its current, actual rate on the basis of rational cost-minimizing efforts at the firm-level (Nikiforos, 2016; Dávila-Fernández et al., 2017). For the sake of convenience, in the remainder of this paper we call this the 'new approach'.

This 'new approach' is based on the microeconomic, firm-level model developed by Nikiforos (2013). Following Kurz (1986), in Nikiforos' analysis the principle of cost minimization drives firms in determining their desired, normal degree of capacity utilization. However, differently from Kurz (1986), the main message of Nikiforos' contribution is that the cost-minimization utilization rate depends positively on the level of demand faced by the firm. In order to achieve this result, a prominent role in the choice of the desired $u_{n}$ is attributed to the functioning of a specific kind of economies of scale.

In Nikiforos (2013) model, firms have to make two choices: which technique of production (represented by the desired capital-labor ratio) to adopt and how intensively to use the capital stock. The latter choice consists in selecting either a single or a double shift system, with the latter corresponding to a higher $u_{n}$. In both cases, the firm produces the same exogenously given quantity $Q$.

Under the double-shift system, the firm owns an amount of capital equal to half the amount used in the single-shift system, but it runs it for double of the time; moreover, in each shift it employs half of the total workforce that it would employ in the single shift. In the double-shift system, employees that work in the second shift (overtime) receive a positive wage differential.

The author starts with the case of only one technique available. The cost of production in the single and double shift systems are assumed to be, respectively: 
$\mathrm{C}^{1}=\left(\mathrm{rK}^{1}+\mathrm{w}_{1} \mathrm{~L}^{1}\right) / \zeta(\mathrm{Q})$

$\mathrm{C}^{2}=\left(\mathrm{rK}^{2}+\mathrm{w}_{1} \mathrm{~L}^{21}+\mathrm{w}_{2} \mathrm{~L}^{22}\right)$

$\mathrm{K}^{\mathrm{i}}$ is the amount of "capital services" (Nikiforos, 2013, p. 523) used in the i-shift system, with $\mathrm{K}^{2}=\mathrm{K}^{1} / 2$; $\mathrm{L}^{1}$ is the number of workers in the single shift, $\mathrm{L}^{2 \mathrm{i}}$ is the number of workers employed, within the double-shift system, in the i shift: $\mathrm{L}^{21}=\mathrm{L}^{22}=\mathrm{L}^{1} / 2 ; r$ is the "unit cost of capital"; $w_{1}$ is basic wage, while $\mathrm{w}_{2}=\mathrm{w}_{1}(1+\mathrm{a})$ is the wage paid in the second shift, with $a$ equal to the wage premium for working overnight.

Nikiforos (2013) assumes that the cost function is such that $\zeta(Q)>1$ and $\zeta^{\prime}(\mathrm{Q})<0$. In his view, this amounts to say that the firm has increasing returns to scale, but at a diminishing rate. Firms take both their output level and the product price as given and choose the system of operation that yields the lower cost of production.

The firm chooses the double-shift system (i.e., higher normal utilization) if the following condition holds:

$[\mathrm{P}+(2+\mathrm{a}) \mathrm{W}] \zeta(\mathrm{Q}) / 2<1$

With $\mathrm{P}=\mathrm{rK}^{1} /\left(\mathrm{rK}^{1}+\mathrm{w}_{1} \mathrm{~L}^{1}\right)$ and $\mathrm{W}=\mathrm{w}_{1} \mathrm{~L}^{1} /\left(\mathrm{rK}^{1}+\mathrm{w}_{1} \mathrm{~L}^{1}\right)$.

Given that $\zeta^{\prime}(\mathrm{Q})<0$, equation (7) implies that when the (exogenously given) quantity produced is higher, the 'premium' for adopting the single-shift system (the one corresponding to lower utilization) is lower. Therefore, a higher $Q$ increases the likelihood that the double-shift system (higher utilization) is the cost-minimizing one.

The economic intuition is summarized as follows: "Production under the single shift system uses simultaneously double the amount of labor compared with the amount of labor used in each shift of the double shift system. The production of $Q$ takes place at a larger scale, but in a shorter period of time. If this larger scale entails some positive returns, production under the single shift system would be relatively cheaper and that in turn would be a reason for the firm to choose this system of production. It follows that if this advantage of large-scale production gradually weakens as production increases, so does the firm's incentive to choose the single over the double shift system [italics added]" (Nikiforos, 2013, pp. 529-530)

The author, then, moves to the case with two techniques available. The second one is said to be "more capital intensive" (ibid., p. 525), because $\mathrm{K}_{\text {II }}>\mathrm{K}_{\mathrm{I}}$ and $\mathrm{L}_{\mathrm{II}}<\mathrm{LI}_{\mathrm{I}}\left(\mathrm{K}_{\mathrm{II}}\right.$ and $\mathrm{K}_{\mathrm{I}}$ are the 'amount of capital' used by the second and the first technique, the same goes for labor). 
In principle, the firm has two choices to make simultaneously: technique of production (i.e., the $\mathrm{K} / \mathrm{L}$ ratio) and system of production (i.e. a single or a double-shift system). Nikiforos' analysis, however, studies the choice of the technique, for each given system of production. Under the single-shift system, ${ }^{4}$ Nikiforos shows that the second technique will be chosen as long as the following inequality holds:

$\frac{\mathrm{r}}{\mathrm{w}_{1}} \frac{\mathrm{K}_{\mathrm{II}}-\mathrm{K}_{\mathrm{I}}}{\mathrm{L}_{\mathrm{I}}-\mathrm{L}_{\mathrm{II}}}<1$

Finally, the case with infinite techniques is presented. The techniques, it is assumed, can be ordered based on their mechanization. A neoclassical 'well-behaved', homothetic aggregate production function with two factors of production (capital and labor) is the analytical tool adopted to conduct the investigation.

$$
Q=G(K, L)
$$

As Nikiforos (2013) shows, when the demand faced by the firm is higher, the double-shift system (the one with a higher $u_{n}$ ) becomes relatively more convenient.

We see Nikiforos' (2013) model as a valuable contribution to production theory. Increasing returns to scale exist in several industries and their implications for firm-level behavior should therefore be explored. We also think that his approach to the issue of the rate of utilization - starting from the cost-minimization problem of the firm, in the same spirit of Kurz (1986) - is the correct one.

In the rest of this paper, however, we will argue that using Nikiforos (2013) model as a justification for the convergence of desired utilization to its realized level in a NeoKaleckian macro model (as in equation 5) requires implausible assumptions and implies a number of inconsistencies. We will therefore conclude that the 'new approach' is not convincing.

\section{Theoretical weaknesses of the new approach}

There are two major weaknesses in the micro-founded 'new approach' described in the previous section. First, the proposed adjustment mechanism is based on a microeconomic model which relies on various restrictive assumptions, some of which are mutually inconsistent (Sec. 2.1). Second, the derivation of the macroeconomic adjustment

\footnotetext{
${ }^{4}$ The double-shift system case is analysed as well.
} 
mechanism from the microeconomic analysis involves a logical leap, that can be justified only by a very peculiar assumption with no economic justification and incompatible with the stated premises of the microeconomic model itself (Sec. 2.2 and 2.3). Moreover, even if one puts aside for the sake of argument the first two points, the existence of autonomous components of demand is sufficient to invalidate the macroeconomic results of this 'new approach' (Sec. 2.4). We substantiate these points in the remainder of this section.

\subsection{Micro-level assumptions}

If Nikiforos (2013) model is to be used as the basis for a macroeconomic adjustment process, its assumptions must hold for an overwhelming majority of firms in the economy. This appears unlikely.

First, it is difficult to believe that all firms in the economy enjoy increasing returns to scale (but at a decreasing rate). Surely some firms do enjoy various forms of increasing returns. But it seems equally plausible that many other firms face constant or decreasing returns. It is not clear why would all production processes display increasing returns - and all of them would experience these increasing returns at a decreasing rate.

Even more important, Nikiforos (2013) models 'increasing returns at a diminishing rate' in a very particular way. In his model, the double shift system displays constant returns to scale. The single shift system displays decreasing returns to scale: for a firm adopting the single shift system, as $Q$ increases the average cost of production increases (because $\left.\zeta^{\prime}<0\right)$. 'Increasing returns to scale' in this model consist in the fact that, for a given output level, passing from the double to the single shift system provides some reduction in total costs. Because this 'premium' from using the single-shift system is assumed to be lower the higher the (given) output level, they are labeled 'increasing but at a diminishing rate'. This is a highly non-standard definition of increasing returns to scale. However, the resulting positive relation between quantity produced and desired rate of utilization depends entirely on, and follows quite directly from, this arbitrary setup.

Second, some assumptions of the model are mutually inconsistent. In an economy in which firms enjoy increasing returns, each sector would be dominated by just one firm. And yet the model assumes that these monopolistic firms take both output and prices as given, failing to use their market power to set prices and increase profits.

In other words, Nikiforos (2013) tells a story about the effects of (a particular type of) increasing returns. As we have already argued, returns to scale are actually not increasing 
in his model. Still, Nikiforos and other proponents of this approach explicitly propose increasing returns to scale as the main justification for the alleged endogeneity of desired utilization, and present their contribution as a model of increasing returns to scale. But if one wants to model increasing returns to scale, one must take into account the fact that increasing returns to scale imply large firms with market power. These firms would determine either the price or the level of production in such a way as to maximize their profits. The assumption that firms are price-takers and take the quantity to be produced as given is not logically consistent with the assumption of increasing returns to scale.

Another problem also arises. Given the specification of the cost functions assumed (eq. 6a and 6b), the single-shift system implies lower unit costs for low levels of $Q$. As $Q$ increases, the unit cost increases, until the point at which the double-shift system becomes more convenient. It is not clear, then, why entrepreneurs should not decide to build multiple small plants, each one producing a small $Q$ and adopting a single-shift system. This exemplifies the contradiction of assuming that unit costs depend on the output level (Q), nonetheless firms give up the possibility of minimizing costs by selecting an optimal $Q$.

As an aside, the treatment of capital in Nikiforos' article does not survive the Cambridge capital critique. ${ }^{5}$ The author assumes that one can order alternative techniques of production based on their 'capital intensity', independently from the distributive variables, an assumption that has been proved untenable (Sraffa, 1960; Samuelson, 1966; see Appendix A in Girardi, 2017 for an intuitive summary of the argument). ${ }^{6}$ This point is related to the fact that the author does not make explicit how he defines capital, whether in value or in physical units. ${ }^{7}$

Even the case labeled by Nikiforos as 'one technique of production' (Nikiforos, 2013, section 5.1) is problematic. What Nikiforos is actually discussing is still a choice between two techniques, being the single-shift system more capital-intensive than the double-shift

\footnotetext{
${ }^{5}$ See Samuelson (1966) and Garegnani (1990) for major overviews of the debate from two participants belonging to opposite sides of the argument. Petri (2004) and Lazzarini (2011) provide more pedagogical expositions of the issues at stake.

${ }^{6}$ It is possible to interpret Nikiforos (2013) model as assuming the existence of only one capital good. In this case, the more mechanized technique would use a higher quantity, in physical term, of this piece of equipment. It is well-known, however, that the resulting relation between factors' prices and desired capital intensity is not robust to allowing for the existence of heterogeneous capital goods (see for example Petri, 2004).

7 This represents a problem in itself, as noticed long ago by Shove in his review of Hicks's The Theory of Wages: "Unfortunately 'capital' is not defined and we are not told how quantities of it are to be measured... But until (these matters) are cleared up it is impossible to follow Mr. Hicks's reasoning" (Shove, 1933, p. 470).
} 
one. Following Kurz (1986, p. 47) - who in turn follows Sraffa - labor in the overnight shift should be seen as incorporating higher labor content per hour than labor in the ordinary shift, which explains why it commands a higher wage per hour. ${ }^{8}$ It follows that the single-shift system displays a higher $\mathrm{K} / \mathrm{L}$ ratio. It is not simply a different system of production, but a different technique of production tout-court.

In conclusion on this point, it is difficult not to regard the micro-level assumptions underlying Nikiforos (2013) contribution as rather restrictive, especially if the model is to be used as the micro-foundation for a macroeconomic mechanism.

\subsection{The passage from micro to macro: a logical leap}

Importantly, even if all these assumptions held at the microeconomic level for all firms, the passage from Nikiforos (2013) microeconomic model to something like equation (5) (that is, the adaptation of the desired rate of utilization to the realized one, at the aggregate level) involves a further leap. Nikiforos' argument implies that, given the assumptions summarized above, the normal degree of capacity utilization will increase when the level of demand for the firm increases. Therefore, at the firm level, we have $\mathrm{u}_{\mathrm{n}}=$ $\mathrm{u}_{\mathrm{n}}(\mathrm{Q})$ and $\mathrm{u}^{\prime} \mathrm{n}(\mathrm{Q})>0$, where $Q$ is the level of demand for the individual firm.

In this setting, making the passage from micro to macro means deriving a relation between the aggregate growth rate of the economy and the normal rate of utilization. Given that in Nikiforos' (2013) model the normal rate of utilization is a function of the average output level of individual firms $(Q)$, this is the same thing as deriving a relation between the aggregate growth rate of the economy and $Q$.

The most obvious way to perform the passage from micro to macro would be to assume that the firm analyzed by Nikiforos' (2013) model is a representative firm, a fictional firm that undertakes all the production in the economy (or industrial sector). This, in general, is not a flawless aggregation process. However, in this case, it would be justified by the assumption of increasing returns: in a one-sector economy with increasing returns, a single firm would indeed emerge, and entry of new firms would not be economically feasible (as they would face higher marginal and average costs than the monopolist).

\footnotetext{
8 Another way to see this is that one cannot assume that labor is homogeneous, if a unit of homogenous labor does not always command the same hourly wage. To solve this problem, one should either allow labor to be heterogeneous (so a unit of labor in the night shift is different from a unit of labor in the morning shift) or assume that an hour of labor in the overnight shift incorporates more units of labor than on hour in the morning shift. The second solution is likely to yield a much simpler model, without any loss of generality.
} 
This aggregation process would not yield the macroeconomic mechanism invoked by the 'new approach' of Nikiforos (2016) and Dávila-Fernández et al. (2017). It would instead yield a model in which any positive growth rate of the economy (even if lower or equal to $\gamma$ ) would cause the normal utilization rate to increase relentlessly, until hitting some possible lower or upper boundary. On a balanced, equilibrium growth path (with the economy growing at the equilibrium rate $\gamma$ ), the utilization rate would converge to either zero or to some upper bound (unless $\gamma=0$ ).

In fact, a more peculiar aggregation procedure is needed to derive, from the micro model in Nikiforos (2013), an equation like equation (5), to be used as a closure to the NeoKaleckian macro model. This procedure is introduced in Nikiforos (2016), when discussing the passage 'from micro to macro', and is based on a further assumption, represented by the following equation: ${ }^{9}$

$$
\dot{\mathrm{Q}}=\varepsilon\left(\mathrm{g}^{\mathrm{K}^{*}}-\gamma\right)
$$

Where $Q$ is the level of output produced by the firm (which the firm takes as exogenous), $\gamma$ is the expected accumulation rate of the economy, $g^{K^{*}}$ is the actual one and $\varepsilon$ is a positive parameter.

Once equation (10) is in place and recalling the assumption that $\mathrm{u}^{\prime} \mathrm{n}(\mathrm{Q})>0$, Nikiforos can derive an equation according to which the normal degree of utilization endogenously increases when the current aggregate rate of accumulation is higher than the expected rate (Nikiforos, 2016, p. 456):

$\dot{u_{n}}=\lambda\left(g^{K^{*}}-\gamma\right)$

where $\lambda$ is a positive parameter.

Equation (11) implies (after straightforward manipulations) that the change in the normal degree of capacity utilization is a positive function of discrepancies between the actual and the normal degree of capacity utilization, which is equivalent to equation (5) above, which we report here for convenience:

$$
\dot{\mathrm{u}}_{\mathrm{n}}=\alpha\left(\mathrm{u}^{*}-\mathrm{u}_{\mathrm{n}}\right)
$$

with $\alpha=\lambda \gamma_{u}$.

9 Dávila-Fernández et al. (2017), by contrast, do not explicitly recognize the existence of an equation like (10) in the background of their model 
This result may seem to validate the Neo-Kaleckian approach. However, the burden of the argument rests entirely on equation (10), according to which the change in the average level of demand faced by firms depends on the discrepancy between the actual and expected growth rate of the economy. This assumption does not seem to have any compelling economic justification, other than the desire to be able to derive a macroeconomic adjustment process that can 'save' the standard Neo-Kaleckian model from instability problems.

Indeed, it is not clear why changes in average firm-level output would be a function of the difference between actual and expected aggregate growth. It is perhaps even more unclear why the variation in firm-level output is assumed to be equal to 0 when the two rates coincide. Yet this is precisely what the 'new approach' assumes (on top of the microlevel assumptions discussed in Section 2.1).

At the cost of repetition, it is important to stress that equation (10) does not simply imply that high aggregate growth translates into a higher increase in output also at the firm level. This, in itself, may be plausible. Equation (10) says something different and much more restrictive: the change in the level of output at the firm level must be a function of the divergence between the expected and the realized growth rate of the economy; and on a balanced growth path, even with a very high rate of growth of the economy, the growth rate of firm-level output must be zero.

A possible way to rationalize these assumptions would be to posit that (a) the rate of growth of the number of firms in the economy is exactly equal to the expected growth rate of the economy $[r]$ and $(b)$ the new firms that are created have the same average size of existing firms. But these assumptions have no economic justification either, especially in a world of increasing returns to scale, as the one we should be dealing with here, in which existing firms would be able to accommodate the increase in demand at a lower average and marginal cost than newly created firms. It is also difficult to imagine how new firms, the moment they are born, could instantaneously reach the average size of existing firms.

Other aspects of this aggregation process are also unclear. Imagine that this NeoKaleckian economy is growing at the equilibrium rate $\gamma$, with the utilization rate at its normal degree. The growth rate of output of each individual firm is exactly zero (otherwise their desired utilization rate would change), the rate of creation of new firms is exactly equal to the expected growth rate of the economy $(\gamma)$ and new firms instantaneously reach the same average size of existing firms. (As we have explained, this peculiar dynamics is what equations 5 and $10 \mathrm{imply)}$. At some point, an exogenous shock 
to the saving rate increases demand. This unexpected increase in demand, however, cannot be met entirely by the creation of new firms - otherwise desired utilization would not increase and the adjustment mechanism would not be triggered. New firms will continue to be created at the previous rate $\gamma$. The unexpected component of the increase in demand must be met by each existing firm increasing their output at a rate exactly equal to the factor $\varepsilon(g-\gamma)$. However, according to equation (10), each individual existing firm would increase its output only after its actual utilization rate has increased above the desired rate (this is implied by equation 10, because $g$ can be higher than $\gamma$ only if $u$ is higher than $u_{n}$ ); yet the actual utilization rate can increase only after output has increased. It is therefore unclear how exactly the adjustment process proposed in Nikiforos (2016) could unfold.

\subsection{Empirical justifications}

The only justification provided by the proponents of the 'new approach' for the assumption constituted by equation (10) is an econometric one. Specifically, Nikiforos (2016) presents a OLS regression of the change in the average number of employees per firm in the US economy on the lagged deviation of the growth rate of US GDP from a trend growth rate, calculated through the HP filter.

We do not see the econometric time-series exercise in Nikiforos (2016) as a substitute for a reasonable economic justification. Indeed, the one we are discussing is a theoretical matter - an issue of internal consistency - rather than an empirical one. But even abstracting from that, the empirical specification does not appear particularly compelling.

First, it is unclear why Nikiforos (2016) uses the change in employment per firm as the outcome variable, when it is output per firm (not employment) that determines the normal utilization rate in his model. Employment per firm is a good proxy for output per firm only if labor productivity growth is zero, while productivity growth has been positive in the period analyzed. Given that data on output per firm is widely available, there seems to be no reason for using an indirect proxy like employment per firm. Second, the number of observations included in the regression is 21 , and yet standard errors are estimated on the basis of asymptotic considerations, not a small sample test. Third, the estimated constant in the regression is positive and significant at the 0.10 significance level, which is inconsistent with equation (10) because it implies a positive trend in the average firm dimension even in the absence of discrepancies between the actual and the expected growth rate. Fourth, it is far from uncontroversial that the trend growth rate estimated through the HP filter can be used as a proxy for firms' expected growth rate. 
Because of how it is constructed, the HP filter includes, in each year $t$, information on future dynamics not available in year $t$.

A more natural and transparent way to assess empirically the consistency of the model proposed by Nikiforos (2016) and Dávila-Fernández et al. (2017) with facts is to look at the overall dynamics of output per firm. From this perspective, the model fares poorly against recent US data. Output per firm has displayed a pronounced increasing trend over the last three decades (Figure 2). The model predicts that this can happen only in a booming economy in which the actual growth rate is persistently higher than the equilibrium growth rate $\gamma$, and actual and desired utilization rates increase continuously. This is a hardly defensible interpretation, given the slowdown of demand after the socalled 'Golden Age' and recent talks of a 'secular stagnation' (Summers, 2014,2016; Teulings and Baldwin, 2014; Hein 2016; Cynamon and Fazzari 2017).

\subsection{Further problems related to the existence of autonomous demand}

Let us put aside, for the sake of argument, the scepticism about the process through which desired utilization would adapt to the current, actual utilization rate, and assume that a mechanism like the one described by equation (5) is effectively at work. Even in this setting, the approach runs into trouble, the moment one admits that there are other sources of demand in the economy, besides domestic investment and induced domestic consumption.

This is particularly the case for such versions of the baseline Neo-Kaleckian model that do not include an endogenous adjustment for the parameter $\gamma$ in the accumulation function (eq. 1), therefore excluding the presence of a mechanism as the one represented by equation (4). In the view of authors such as Dávila-Fernández et al. (2017, p. 5), the parameter $\gamma$ should be assumed to be exogenous, because "making autonomous investment [the parameter $\gamma$ ] an endogenous variable (...) would eliminate all roles for uncertainty and animal spirits in long run growth". ${ }^{10}$

\footnotetext{
${ }^{10}$ In their critique of Lavoie (2016), the authors propose to replace, as a closure to the Neo-Kaleckian model, an 'adaptive expectations' mechanism analogous to equation (4) with equation (5). See Lavoie (2018) for a reply to Dávila-Fernández et al. (2017).
} 
Let us accept their premises but assume, more realistically, that there is some positive level of autonomous consumption in the economy, which grows at some given rate. ${ }^{11} \mathrm{We}$ denominate autonomous consumption as $Z$, while $z$ is the ratio $Z / K$. In terms of the stylized Neo-Kaleckian model that we have used here, equation (2) would become:

$$
\mathrm{g}^{\mathrm{S}}=\mathrm{S} / \mathrm{K}=\mathrm{S}_{\mathrm{p}} \Pi \mathrm{u} / \mathrm{v}-\mathrm{z}
$$

And the short-run equilibrium would be as follows:

$$
u^{*}=\frac{\left(\gamma-\gamma_{u} u_{n}+z\right) v}{s_{p} \Pi-v \gamma_{u}}
$$

The resulting dynamic system - described by equations $1,2 b, 3 b$ and 5 - would be a system of two differential equations:

$$
\begin{aligned}
& \dot{\mathrm{z}}=\mathrm{z}\left(\mathrm{g}^{\mathrm{Z}}-\mathrm{g}^{\mathrm{K}}\right)=\mathrm{z}\left[\mathrm{g}^{\mathrm{Z}}-\gamma-\gamma \mathrm{u}\left(\mathrm{u}^{*}-\mathrm{u}_{\mathrm{n}}\right)\right] \\
& \dot{\mathrm{u}}_{\mathrm{n}}=\alpha\left(\mathrm{u}^{*}-\mathrm{u}_{\mathrm{n}}\right)
\end{aligned}
$$

It is straightforward to see, by imposing $\dot{z}=\dot{u}_{n}=0$, that no equilibrium solution exists, unless the exogenous parameter $\gamma$ coincides, by a fluke, with $g^{Z}$. Autonomous consumption (or any other component of demand different from domestic consumption and investment, such as exports and public spending) would need to grow, for some reason, at a rate equal to the constant in the accumulation function. This is not particularly surprising. The presence of the autonomous parameter $\gamma$ in the accumulation function prevents the full adjustment of productive capacity to aggregate demand.

To avoid any confusion, it is worth noting that our argument does not require the assumption that the rate of growth of autonomous demand is constant and/or exogenous to domestic economic conditions. All we are assuming here is that (1) some source of demand other than domestic induced consumption and investment exists and is not-

${ }^{11}$ Starting from Serrano and his Sraffian supermultiplier model (1995), a recent stream of research stresses the role played by autonomous demand in driving economic growth. See for example Bortis (1997), Cesaratto et al. (2003), Freitas and Serrano (2015). As shown by Allain (2015) and Lavoie (2016), the basic insights of the Sraffian Supermultiplier model can be produced by modifying some key assumptions of the canonical Neo-Kaleckian model. See also Nah and Lavoie (2017), Fiebiger (2017) and Fiebiger and Lavoie (2017). 
negligible; ${ }^{12}(2)$ its growth rate is not exactly equal to $\gamma$ (the constant in the Neo-Kaleckian investment function, dictated by the animal spirits of capitalists). This is sufficient to lead the model astray.

\section{Conclusions}

A major critique against the Neo-Kaleckian growth model, almost since its inception, concerns its failure to reconcile actual and normal utilization rates in equilibrium. The model effectively assumes that firms do not attempt to reach their normal rate of capacity utilization.

The principal line of defence against this critique proposes a reversal of the standard chain of causality: rather than firms trying to reach their desired utilization rate, it would be the desired utilization rate that would endogenously adjust to the actual, realized one. This line of reasoning has traditionally been based on a 'conventionalist' argument, which, however, did not manage to settle the issue and persuade the many critics.

Recent contributions have tried to revive this old proposal, giving it new (nonconventionalist) foundations (Nikiforos, 2013 and 2016; Dávila-Fernández et al., 2017). They attempt to justify the same mechanism of convergence of the normal utilization rate to its actual value, on the basis of a micro-founded cost-minimization process, paired with the presence of a very specific form of increasing returns to scale.

In this article, we have argued that this new justification cannot be considered satisfactory. Our critique is organized in three, mutually independent, parts.

First, the microeconomic model that should prove the endogeneity of the normal degree of capacity utilization to variations in the level of demand at the firm-level (Nikiforos, 2013) relies on various restrictive assumptions. All firms are assumed to face a very specific type of returns to scale, which the proposers of the approach qualify as 'increasing at a diminishing rate'. However, as we have shown, returns are actually not increasing in the model. At the same time, inconsistently with the claim of modeling

\footnotetext{
12 Neglecting autonomous demand altogether could be justified by asymptotic considerations, if it is assumed that the growth rate of autonomous demand is lower than the expected growth rate. If the inequality $\gamma>g^{Z}$ held, $z$ would slowly, asymptotically tend to 0 , and so would $\dot{z}$ in equation (12). There is no economic reason, however, to assume that the expected growth rate is systematically higher than the growth of autonomous demand. Empirical evidence (Girardi and Pariboni, 2015 and 2016) suggests that, to the contrary, the share of autonomous demand in the economy tends to be sizeable.
} 
increasing returns to scale, these firms are assumed to take both product price and output as given.

Second, the derivation of the macroeconomic adjustment mechanism - which provides the closure for the Neo-Kaleckian growth model - from the microeconomic model of Nikiforos (2013) involves a logical leap. This can be justified only by a very peculiar assumption about the relation between the growth rate of the economy and the level of demand per firm, which has no plausible economic explanation. In section 2.3, we have also argued that the empirical argument advanced to justify the micro-to-macro passage (Nikiforos, 2016) is not convincing either. In fact, the strong increasing trend in output per firm experienced by the US economy in the last three decades (Figure 2) is very hard to reconcile with the model.

Third, we discuss a recent contribution to Neo-Kaleckian growth modeling (DávilaFernández et al., 2017), which builds on the micro-founded approach examined here. We find that even if one puts aside for the sake of argument the perplexities regarding the mechanism of endogenization of the normal rate of utilization, the existence of autonomous components of demand, defined here as any source of demand which growth rate is not dictated by the rate of domestic accumulation, is sufficient to create troubles to their Neo-Kaleckian macro model. 


\section{References}

Allain, O. (2015). Tackling the instability of growth: A Kaleckian-Harrodian model with an autonomous expenditure component. Cambridge Journal of Economics, 39(5), 1351-1371. Amadeo, E. J. (1986). Notes on capacity utilisation, distribution and accumulation. Contributions to Political Economy, 5, 83-94.

Bortis, H. (1997). Institutions, Behaviour and Economic Theory: A Contribution to ClassicalKeynesian Political Economy. Cambridge University Press, Cambridge.

Cesaratto, S. (2015). Neo-Kaleckian and Sraffian controversies on the theory of accumulation. Review of Political Economy, 27(2), 154-82.

Cesaratto, S., Serrano, F., Stirati, A. (2003). Technical change, effective demand and employment. Review of Political Economy, 15(1), 33-52.

Cynamon. B.Z., Fazzari, S.M. (2017). Secular Demand Stagnation in the $21^{\text {st }}$ Century U.S. Economy. Draft prepared for INET Secular Stagnation Conference, December 15, 2017. Dallery, T., van Treeck, T. (2011). Conflicting claims and equilibrium adjustment processes in a stock-flow consistent macroeconomic model. Review of Political Economy, 23(2), 189-211.

Dávila-Fernández M.J., Oreiro, J.L., Punzo, L.F. (2017). Inconsistency and overdetermination in neo-Kaleckian growth models: A note. Metroeconomica, doi.org/10.1111/meca.12190.

Dutt, A.K. (1984). Stagnation, income distribution and monopoly power. Cambridge Journal of Economics, 8(1), 25-40.

Dutt, A.K. (1990). Growth, distribution and uneven development. Cambridge University Press, Cambridge.

Fiebiger, B. (2017). Semi-autonomous household expenditures as the causa causans of postwar US business cycles: the stability and instability of Luxemburg-type external markets. Cambridge Journal of Economics, doi.org/10.1093/cje/bex019. 
Fiebiger, B., Lavoie, M. (2017). Trend and business cycles with external markets: Noncapacity generating semi-autonomous expenditures and effective demand. Metroeconomica, doi.org/10.1111/meca.12192.

Freitas, F., Serrano, F. (2015). Growth rate and level effects, the stability of the adjustment of capacity to demand and the Sraffian Supermultiplier. Review of Political Economy, 27(3), 258-281.

Garegnani, P. (1990). Quantity of Capital, in Eatwell, J., Milgate, M., Newman, P. (eds.), The New Palgrave: Capital Theory. London: Macmillan, pp. 1-78.

Girardi, D. (2017). Old and New Formulations of the Neoclassical Theory of Aggregate Investment: A Critical Review. UMass Amherst Economics Working Papers, 2017-03, http://www.umass.edu/economics/publications/2017-03.pdf

Girardi, D., Pariboni, R. (2015). Autonomous demand and economic growth: some empirical evidence. Centro Sraffa Working Paper no. 13.

Girardi, D., Pariboni, R. (2016). Long-run Effective Demand in the US Economy: An Empirical Test of the Sraffian Supermultiplier Model. Review of Political Economy, 28(4), 523-544.

Hein, E. (2016). Secular stagnation or stagnation policy? A post-Steindlian view. European Journal of Economics and Economic Policies: Intervention, 13(2), 160-171.

Hein, E., Lavoie, M., Van Treeck, T. (2012). Harrodian instability and the normal rate of capacity utilization in Kaleckian models of distribution and growth - a survey. Metroeconomica, 63(1), 39-69.

Kurz, H. (1986). 'Normal' positions and capital utilization. Political Economy, 2(1), 1, 3754 .

Lavoie, M. (1992). Foundations of Post-Keynesian Economic Analysis. Elgar, Aldershot. Lavoie, M. (2014). Post-Keynesian Economics. New Foundations. Elgar, Cheltenham. 
Lavoie, M. (2016). Convergence towards the normal rate of capacity utilization in neoKaleckian models: The role of non-capacity creating autonomous expenditures. Metroeconomica, 67(1), 172-201.

Lavoie, M. (2018). Inconsistencies in the note of Dávila-Fernández, Oreiro and Punzo. Metroeconomica, DOI: 10.1111/meca.12202.

Lavoie, M., Rodriguez, G., Seccareccia, M. (2004). Similarities and discrepancies in postKeynesian and Marxist theories of investment: a theoretical and empirical investigation. International Review of Applied Economics, 18(2), 127-149.

Lazzarini, A. (2011). Revisiting the Cambridge Capital Controversies: A Historical and Analytical Study. Pavia University Press, Pavia.

Nah, W.J., Lavoie, M. (2017). Long-run convergence in a neo-Kaleckian open-economy model with autonomous export growth. Journal of Post Keynesian Economics, 40(2), 223238.

Nikiforos, M. (2013). The (normal) rate of capacity utilization at the firm level. Metroeconomica, 64(3), 513-538.

Nikiforos, M. (2016). On the 'utilization controversy': A theoretical and empirical discussion of the Kaleckian model of growth and distribution. Cambridge Journal of Economics, 40(2), 437-467.

Pasinetti, L.L. (1966). Paradoxes in Capital Theory: A Symposium: Changes in the Rate of Profit and Switches of Techniques. The Quarterly Journal of Economics, 80(4), 503-517.

Petri, F. (2004). General equilibrium, capital and macroeconomics. Edward Elgar, Cheltenham. Rowthorn, R. (1981). Demand real wages and economic growth. Thames Papers in Political Economy, 1-39.

Samuelson, P.A. (1966). A summing up. The Quarterly Journal of Economics, 80(4), 568-583.

Serrano, F. (1995). Long period effective demand and the Sraffian Supermultiplier. Contributions to Political Economy, 14, 67-90. 
Setterfield, M. (2017). Long-run variation in capacity utilization in the presence of a fixed normal rate. New School for Social Research Working Papers 1704.

Shaikh, A. (2016). Capitalism: Competition, conflict, crises. Oxford University Press, Oxford. Shove, G.F. (1933). Review of The Theory of Wages by J.R. Hicks. The Economic Journal, 43(171), 460-472.

Skott, P. (2012). Theoretical and empirical shortcomings of the Kaleckian investment function. Metroeconomica, 63(1), 109-138.

Skott, P. (2018). Challenges for post-Keynesian macroeconomics. UMass Amherst Working Paper 2018-03.

Sraffa, P. (1960). Production of Commodities by Means of Commodities: Prelude to a Critique of Economic Theory. Cambridge University Press, Cambridge.

Summers, L.H. (2014). Reflections on the "New Secular Stagnation Hypothesis", in Teulings, C., Baldwin, R. (eds). Secular Stagnation: Facts, Causes and Cures. London: CEPR Press, pp. 27-38.

Summers, L.H. (2016). The age of secular stagnation. Foreign Affairs. Available at: http:// larrysummers.com/2016/02/17/the-age-of-secular-stagnation/.

Teulings, C., Baldwin, R. (eds) (2014). Secular Stagnation: Facts, Causes and Cures. London: CEPR Press. 


\section{Figures}

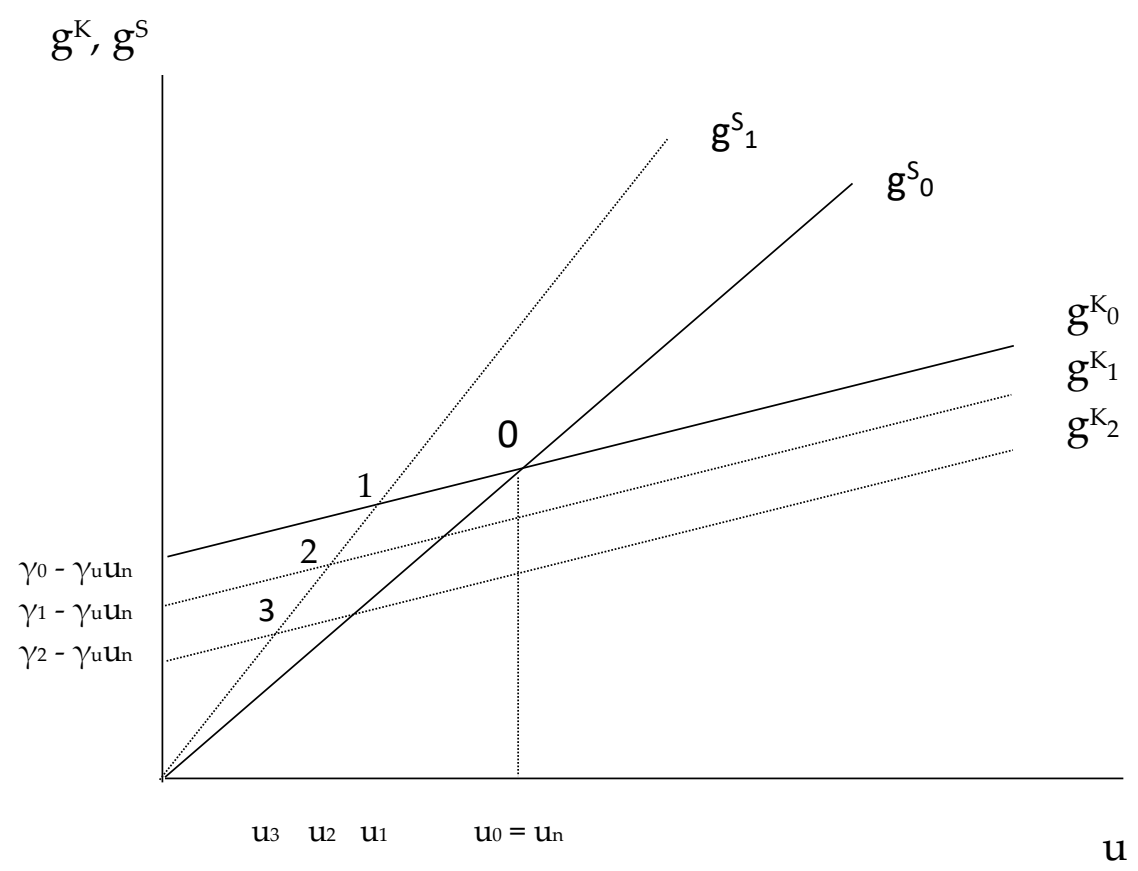

Figure 1: the effects of an increase in the marginal propensity to save in a NeoKaleckian model with adaptive expectations: $\Delta \gamma=\theta\left(\mathrm{u}^{*}-\mathrm{u}_{\mathrm{n}}\right)$ 


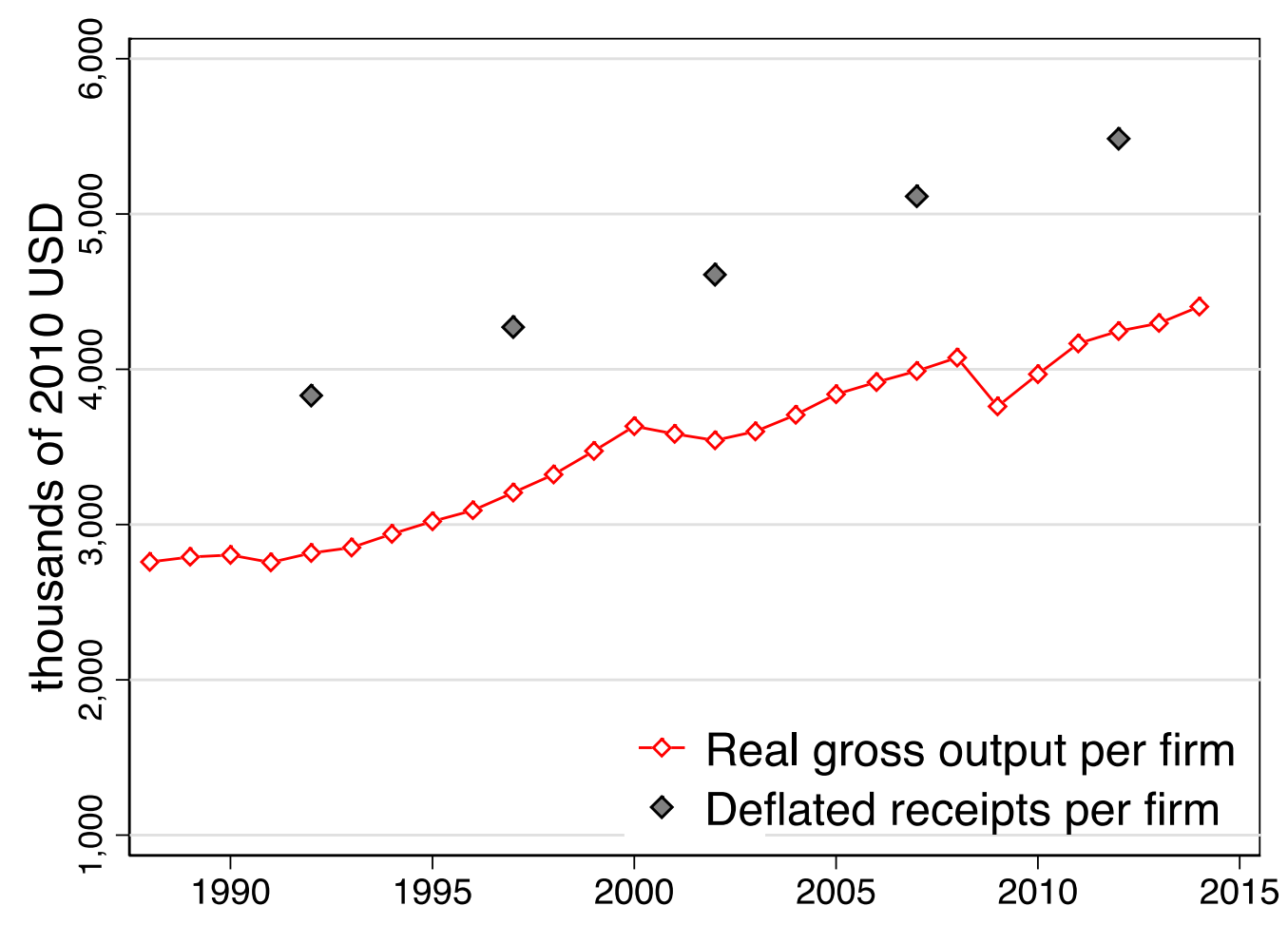

Figure 2: average output per firm in the US economy (1988-2014)

Number of firms and receipts data from SBA (https://www.sba.gov/advocacy/firm-size-data). Receipts are available only for Census years $(1997,2002,2007$ and 2012). Gross output for private industries retrieved from BEA (https://www.bea.gov/industry/gdpbyind data.htm). Data deflated using the implicit GDP deflator for the US economy with base year 2010, from Federal Reserve Economic Data (https://fred.stlouisfed.org). All series were retrieved on May 5, 2018. 